\title{
La hidropolítica y las relaciones exteriores de China en el complejo hídrico del Himalaya; los casos de Nepal e India
}

\author{
Miguel Ángel Medina Abellán*
}

\begin{abstract}
RESUMEN
Los diez sistemas de ríos principales del continente asiático nacen en el Himalaya, la gran mayoría, en la enorme meseta tibetana. China es uno de los países con más ríos transfronterizos en el mundo, solo superado por Rusia y Argentina. La torre de agua de Asia se encuentra en una posición que le confiere un enorme poder e influencia, y las decisiones que adopte en el campo de sus relaciones hidráulicas con el resto de países tiene un alcance regional, continental y, posiblemente, global. La gestión de sus dieciséis ríos transfronterizos puede afectar la disponibilidad de agua de muchos países río abajo, con afectación directa al acceso a los recursos hídricos de catorce países en el continente asiático y de casi tres billones de personas, es decir casi la mitad de la población mundial
\end{abstract}

El objetivo del presente artículo es analizar el comportamiento hidráulico chino en el complejo del Himalaya, a partir de dos casos de estudio: las relaciones de China con Nepal e India. Se pretende así contribuir al debate sobre, por una parte, los factores explicativos del comportamiento hídrico de la potencia asiática, prestando especial atención a la importancia de la meseta tibetana y, por el otro, al debate académico sobre la estrategia china en relación con uno de los recursos más apreciados del planeta, el agua. China cuenta hoy en día con unas 90.000 infraestructuras hidráulicas, contando presas, diques y proyectos de desvío de agua, y sus intereses hídricos abarcan tanto ríos internos — que acusan la escasez y la sequía con más gravedad, como el Amarillo o el Yangtzé- como los ríos transfronterizos internacionales, lo que conlleva de inmediato una amenaza para los países con los que comparte estos ríos - como el Brahmaputra.

El principal argumento es que la política china en el Himalaya es un eslabón más en el intento chino de consolidar su presencia política y estratégica en diferentes partes del mundo. Las relaciones hídricas chinas se deben analizar en el contexto de la política exterior del gigante asiático en la última década, marcada por su expansionismo, su cristalización como gran potencia mundial, y su estilo de política exterior a escala global.

El artículo se estructura de la siguiente forma. El primer apartado contiene el marco teórico y analítico del articulado, empezando por el paraguas conceptual que nos ofrece la hidropolítica para entender el comportamiento en términos hídricos de China en el espacio del Himalaya, en base a dos conceptos principales: hidrohegemonía e hidrodominación. El segundo apartado contiene una disección analítica del Himalaya como complejo hídrico y el estudio de los casos relevantes para entender el comportamiento de China en el sistema himalayo; Nepal e India. El análisis de los factores explicativos de la política hídrica china, a nivel endógeno y exógeno, así como la estrategia seguida por Pekín, sustentan el tercer apartado del documento. Las conclusiones y consideraciones finales cierran el presente artículo.

\section{Palabras clave}

Himalaya; China: hidropolítica; hidrohegemonía; hidrodominación.

\section{Tithe}

Hydropolitics and China's external relations in the Himalayas: the cases of Nepal and India
* Miguel Ángel MEDINA ABELLÁN, Doctor en Relaciones Internacionales por la Universidad de Cambridge (Reino Unido). Profesor de Relaciones Internacionales en la Universidad Abat Oliba-CEU y en el CEI International Affairs, Escuela Diplomática de Barcelona. Su principal área de investigación es la geopolítica euromediterránea.

Contacto: m.medina.abellan@g mail.com

Recibido: 30/05/2020

Aceptado:

12/10/2020

\begin{abstract}
Asia's ten main river systems originate in the Himalayas, most of them in the enormous Tibetan plateau, the Roof of the World, which holds a unique geostrategic importance in the world and is controlled by China. This is one of the countries with the most trans-boundary rivers in the world, second only to Russia and Argentina. The Asian water tower holds a position that gives it enormous power and influence, and the possible decisions Beijing can make regarding its hydraulic relations with the rest of the countries transcend the Himalayas and have a regional, continental and possibly global scope. The management of its 16 transboundary rivers can affect the availability
\end{abstract}

DOI:

https://doi.org// 0.15366/relacionesinternacionales2020.45.010

Formato de citación recomendado:

MEDINA ABELLÁN, Miguel Ángel (2020). "La hidropolítica y las relaciones exteriores de China en el complejo hídrico del Himalaya; los casos de Nepal e India”, Relaciones Internacionales, n 45, pp. 227-250. 
of water in many downstream countries, directly affecting access to water resources in 14 of them on the Asian continent and almost three billion people, that is, almost half of the world population

This article aims to analyse Chinese hydraulic behaviour in the Himalayan complex, based on two case studies: Nepal and India. On the one hand, the present piece of work contributes to the debate on the explanatory factors of Chinese water behaviour, both domestically and internationally. On the other, it traces the academic debate on Chinese strategy in relation to one of the most valued resources on the planet, water. China has embarked upon 90,000 projects on hydraulic infrastructure, including dams, dikes, water diversion projects, river basin and river water transfers. These megaprojects affect both internal rivers - which suffer from the most serious scarcity and drought, such as the Yellow river or the Yangtze- as well as international transboundary rivers, which immediately pose a threat to the countries with which it shares these rivers - such as the Brahmaputra. The Himalayas represent a strategic enclave of extraordinary significance in the international system, but it remains unknown and under studied in Spain, especially the case of Tibet, the Himalayas, and Sino-Indian relations.

The theoretical framework guiding this research comes from hydropolitics, coined for the first time in 1979 by Waterbury and that holds significant explanatory power for the present work. The analysis uses hydropolitics as the systematic investigation of the interaction between riparian states, non-state actors and other participants in relation to the authorized allocation and / or use of national and international water resources. Hydro-politics is also related to the capacity of geopolitical institutions to manage shared water resources in a politically sustainable way. Two main concepts related to hydropolitics frame the research. On the one hand, hydrohegemony, understood as the preponderance position of a country within a given water complex. On the other, that of hydrodomination, highlighting the behaviour of a country trying to impose its dominion. Both concepts are notably intertwined but do not mean, or imply, the same, and both will illuminate the findings of the study of China' water policy in the Himalayas.

The text is structured as follows. First, it sets out the rationale of the paper, laying out the main objectives, the relevance of the topic under scrutiny and the appropriateness of the selected case studies. The second section bears the theoretical part of the paper and contains two main aspects. First, it depicts water as a geopolitical problem and outlines why water is a geopolitical asset. Second, it explores hydropolitics as the main explanatory approach and the two main concepts therein, hydrohegemony and hydrodomination. The main empirical part of the article is found in the third section, and unfolds by presenting the Himalayas, highlighting its strategic standpoint, namely as a key hydrological complex. It then analyses two meaningful case studies, which help address the two main questions posed by the paper. Sketching out China's hydropower in Tibet as the main domestic factor, as the Tibetan plateau is the main source of hydrological power to China, the paper focuses on China's projects in Nepal as the first case under the prism of the study- China is returning and increasingly stepping into this territory through several waterrelated projects. Then, the paper draws attention to Sino-Indian relations and, concretely, to the relations over the Sikkim region and the Chinese projects in the Brahmaputra.

The summary outlines some findings of the analysis of the case studies. It states that China takes advantage of its hydrohegemony and of the current international context to impose its preferences over water relations and to pursue a unilateral, assertive, aggressive hydropolicy. China' water context cannot be neglected, but the crisis of multilateralism and lingering geopolitical disputes in the wider Himalayan region are external factors that shape Chinese behaviour.A second finding is related to geography, as geographical considerations always matter. China's control over the Tibetan plateau and its transboundary water character provide this country with a position which allows this country to exert some hegemony and domination vis-à-vis its riparian neighbours. This is not merely a geographical reality, but a geopolitical imperative that China always uses as a trump card.Third, China's hydropolicy in Nepal and India seems to indicate a huge degree of continuity in Mao's the bigger, the better policy. Beijing keeps its political strategy to become the world's leading superpower, and this needs naturally enormous infrastructure projects, massive investments, and a global quest for natural resources. Some of the concrete projects presented, such as the South-to-North Water Diversion Project, are remarkable in that sense. The final conclusions and considerations close this article. The paper zooms out and refers to the relevance of the Himalayas, with the special case of the Tibetan plateau, to Chinese behaviour and to hydropolitics. It also proposes some topics and theoretical approaches for future research.

The main argument of the article is that Chinese water policy in the Himalayas should be conceived as one more step in China's attempt to consolidate its political and strategic presence in different parts of the world. Chinese relations must be analyzed in the context of its foreign policy over the last decade, marked by its expansionism, its crystallization as a great world power and the fostering of mega projects and initiatives on a global scale. In short, maybe the most hydropolitical imperative of China is Why should I cooperate if I can dominate?

\section{KEYWORDS}

Himalayas; China; hydropolitics; hydrohegemony; hydrodomination. 


\section{ntroducción}

La cordillera del Himalaya es el altiplano más alto y extenso del mundo, la tercera reserva de agua dulce del planeta, y su vasto depósito de hielo es el mayor en la Tierra después del Ártico y de la Antártida, por lo que también recibe el calificativo de Torre de Agua de Asia (Chellaney, 20I I, p. 97; Zhang y Li, 2018b, p. 699; Engelke y Michel, 2019, p. 2). Se trata de un sistema de enorme importancia hidrológica para los 240 millones de habitantes de sus montañas, para los ocho países que lo conforman, para los casi dos billones de personas que viven en los cauces bajos de los diferentes ríos que tienen aquí su nacimiento y, en último lugar, para la humanidad (Wester, Mishra, Mukherji y Shrestha, 2019, p. v).

Este altiplano, considerado el Tercer Polo, es actualmente la principal fuente de agua de toda Asia (Wester, Mishra, Mukherji y Shrestha, 2019, p. 3). Los diez sistemas de ríos principales del continente asiático nacen en el Himalaya —la gran mayoría, en la enorme meseta tibetana-, como son el Mekong, el Yangtzé, el Indo, el Salween, el Brahmaputra o el Amarillo, que riegan territorios donde vive casi la mitad de la población mundial. El Himalaya es un caso de estudio significativo para analizar las relaciones hidropolíticas por tres razones principales: los desequilibrios en la disponibilidad de agua de los países implicados, tanto aguas arriba como aguas abajo; la gobernanza regional del agua y la ausencia de gestión transnacional cooperativa o integrada; y la fuerte interrelación de las dinámicas geopolíticas con las dinámicas hidráulicas en este complejo (Engelke y Michel, 2019, p. 10).

\section{El sistema himalayo}

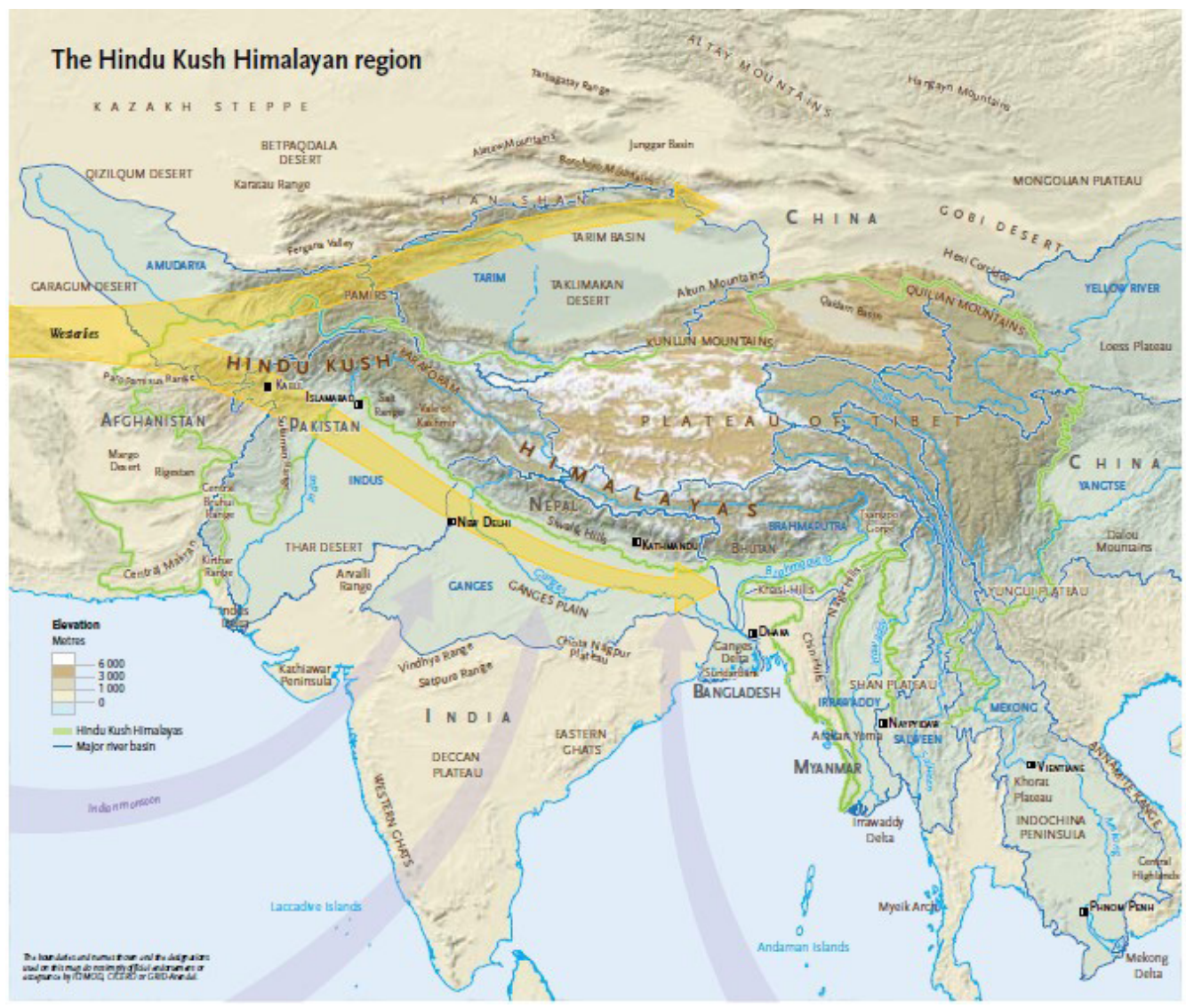

Fuente: Engelke y Michel, 2019. 
China es uno de los países con más ríos transfronterizos en el mundo, solo superado por Rusia y Argentina. China ocupa un lugar privilegiado en el contexto himalayo, y es el país río arriba para muchos países de Asia, ergo las decisiones que adopte en el campo de sus relaciones hidráulicas con el resto de países tienen alcance regional, continental y, posiblemente, global. La gestión de sus 16 ríos transfronterizos puede afectar la disponibilidad de agua de muchos países río abajo, con afectación directa al acceso a los recursos hídricos de 14 países en el continente asiático y de casi tres billones de personas, casi la mitad de la población mundial (Li y Wu, 20I7, p. 59). A nivel interno, por el contrario, la foto de China es diferente. Posee solo el $6 \%$ de los suministros de agua dulce del planeta, que deben cubrir las necesidades de una quinta parte de los ciudadanos del mundo. $Y$ a esto se añade el desequilibrio poblacional y de acceso a los recursos en el interior del país.

El objetivo de las páginas que siguen a continuación es analizar las relaciones hidráulicas de China en el complejo del Himalaya y contribuir al debate académico sobre uno de los vectores de la política exterior del gigante asiático. El texto se centra en el análisis de, por una parte, los factores explicativos del comportamiento hídrico de China. Entre los factores endógenos, se presta especial atención al Tíbet y a la situación hídrica de China a nivel interno. Los factores exógenos analizados son las relaciones políticas y diplomáticas de China con otros países de la región. Por otra parte, el presente artículo contribuye al debate académico sobre la estrategia hídrica china y cómo Pekín gestiona su considerable hidropoder. China cuenta hoy en día con unas 90.000 infraestructuras hidráulicas, contando presas, diques y proyectos de desvío de agua, y sus intereses hídricos abarcan tanto ríos internos — que acusan la escasez y la sequía con más gravedad, como el Amarillo o el Yangtzé- como los ríos transfronterizos internacionales, lo que conlleva de inmediato una amenaza para los países con los que comparte estos ríos - como el Brahmaputra o el Mekong (Delgado y Teano, 20I9, p. I0I).

Dos casos de estudio forman el sustento empírico. En primer lugar, las relaciones sinonepalíes — catalogadas como el apretón de manos a través del Himalaya en la actualidad- ponen de relieve varias de las contingencias de la política exterior china en términos hídricos. En segundo lugar, el artículo analiza las relaciones hidrológicas entre los dos gigantes asiáticos; China e India. Por motivos de economía expositiva, el presente artículo se centra solo en dos episodios de las relaciones hídricas sino-indias, como son los proyectos hidráulicos chinos en el río Brahmaputra, en la región de Arunachal Pradesh y la gestión de la problemática por la región india del Sikkim.

El principal argumento del articulado es que la política hídrica china en el Himalaya es un eslabón más en el intento chino de consolidar su dominación a nivel regional.Y no debemos olvidar la creciente presencia china en diferentes partes del mundo, destacando, aparte del continente asiático, el África subsahariana y América Latina. Las relaciones hídricas chinas se deben analizar en el contexto de la política exterior del gigante asiático en la última década, y siempre teniendo en cuenta los objetivos políticos y económicos de Pekín a medio y largo plazo. Dicha política pasa por una estrategia exterior expansionista y por sus proyectos e iniciativas a escala continental y global - como la campaña del Go West, la nueva ruta de la seda, las inversiones en numerosos países africanos o la presa de las Tres Gargantas-. A modo de ejemplo, China participa actualmente en la financiación y la construcción de unos 350 proyectos hidrológicos a nivel mundial, a diferentes niveles y particularmente en países asiáticos y africanos de renta media y baja (Urban, Siciliano y 
Nordensvard, 2018, p. 748).

Y no debemos olvidar los factores exógenos de carácter estructural, como son la respuesta a los desafíos de la globalización, la desaceleración económica o la crisis del sistema liberal internacional, basado en el multilateralismo y las instituciones de Bretton Woods. Se trata de analizar la dimensión hídrica de la política exterior china ampliando el foco más allá de las relaciones bilaterales o regionales y resaltando la importancia del reparto global de los recursos naturales, las dinámicas políticas y económicas a escala global y las consecuentes batallas geopolíticas. El presente artículo trata, en otras palabras, de analizar algunas de las contingencias geopolíticas a las que se enfrenta China en el panorama actual (Yuan, 2018, p. 70).

Las páginas que siguen a continuación se estructuran de la siguiente manera. El primer apartado contiene el marco teórico y analítico del articulado, empezando por el paraguas conceptual que nos ofrece la hidropolítica para entender el comportamiento en términos hídricos de China en el espacio del Himalaya, en base a dos conceptos principales: hidrohegemonía e hidrodominación. A continuación, el segundo apartado contiene una disección analítica del Himalaya como complejo hídrico, y se presentan los factores endógenos que determinan la política hidráulica china puertas afuera, prestando especial atención a la meseta tibetana y a la configuración hídrica china. En segundo término, se presentan los dos casos de estudio que nos sirven para entender el comportamiento de China en el sistema himalayo; Nepal e India. El tercer apartado contiene el análisis de los factores explicativos de la política hídrica china, así como la estrategia seguida por Pekín. Las conclusiones y consideraciones finales cierran este artículo.

\section{A modo de marco teórico: el agua como problema político y el concepto de hidropolítica}

Un informe del Programa de las Naciones Unidas para el Desarrollo alertaba en 2016 sobre la escasez de agua en el mundo y las repercusiones de esta escasez a nivel global (PNUD, Informe sobre Desarrollo Humano, 2016, p. 38). La escasez o abundancia de agua, per se, no es una fuente de tensiones internacionales, pero la gestión de los recursos hídricos sí que puede considerarse un vector geopolítico esencial (Selby y Hoffmann, 2014, p. 36I). No se trata solo de un recurso natural de primer orden, sino de un factor vertebrador de las relaciones internacionales con una enorme carga política, estratégica, económica y sociocultural. Es el carácter geopolítico del agua a escala global el que centra el foco del análisis. Es un recurso en constante movimiento que no suele concebir fronteras físicas ni políticas, cada vez más escaso y que cada vez conlleva una carga política y estratégica más importante (Giordano y Wolf, 2003). I 45 países comparten actualmente 263 cuencas hidrográficas transfronterizas, de los cuales más de 30 están ubicados en su totalidad en territorios de cuencas fronterizas. Dos de cada cinco habitantes del mundo viven en cuencas hidrográficas internacionales compartidas por más de un país lo que ha llevado a hablar a los analistas de la interdependencia hidrológica (Jiménez, 2009, p. 36).

El agua no suele aparecer en el debate público internacional con la misma intensidad que los asuntos étnicos, las armas de destrucción masiva, el petróleo, el terrorismo o las dictaduras. Sin embargo, se trata de un elemento con una importancia geopolítica inmensa, y generalmente poco o nada reconocida, seguramente no como factor principal de los conflictos internacionales, pero 
sí en el fomento de la cooperación a nivel internacional (Selby, 2005, p. 330). Las relaciones hídricas también son relaciones de poder, y el control chino de los ríos del continente tiene enormes consecuencias geoestratégicas; no podemos entender las relaciones bilaterales y regionales de la potencia asiática con el resto de países sin tener en cuenta la posición hídrica china (Chellaney, 20II, p. 5I).

Los problemas por el agua nunca son problemas solo por el agua, si no que en buena medida reflejan o son la consecuencia de la habilidad relativa de los diferentes estados y actores implicados para gestionar problemas de mayor calado, en general políticos, económicos y sociales, incluyendo los propios asuntos hídricos (Selby, 2005, p. 333). El agua es un bien preciado cuyo control subyace en el centro de muchos conflictos en el continente asiático, que puede llevar a convertirse en un vector político clave a escala global debido a su posible ramificación con diversas coordenadas históricas, económicas y socioculturales (Chellaney, 20I I, p. 3).

El marco teórico del articulado es el de la hidropolítica. Acuñada por primera vez por John Waterbury en 1979, se define como "la capacidad asociada a las instituciones con carácter geopolítico para manejar y gestionar los recursos hídricos compartidos de manera sostenible”. Es decir, la capacidad de administrar este recurso de tal manera que todas las partes implicadas tengan acceso al agua, disminuya el uso indebido del recurso y se eviten conflictos derivados del acceso o falta de acceso al mismo (Waterbury, 1979). El término ha sido utilizado en números estudios publicados en la producción académica anglosajona, principalmente en relación con Oriente Medio y en menor medida Asia (Kauffer, 20I I, p. I59). Posteriormente ha habido interesantes reformulaciones del concepto, la mayoría eso sí restringidos al estudio sistemático del conflicto y de la cooperación entre los Estados acerca de los recursos hídricos que transcienden las fronteras. Se pueden subrayar en este sentido los trabajos de Elhance (1999), Turton (2002) o Mgquba y Majozi (2020). Se ha llegado a afirmar que la gestión de aguas transfronterizas es tan relevante como la gestión de las fronteras internacionales de un país, ya que puede llegar a comprometer la soberanía y el interés nacional de aquellos países que comparten estos recursos hídricos (Brito y Missio, 2019, p. 35).

El presente artículo usará la acepción de la hidropolítica como la investigación sistemática de la interacción entre estados, actores no estatales y otros participantes, en relación con la asignación autorizada y/o el uso de recursos hídricos nacionales e internacionales (Mgquba y Majozi, 2020, p. I55). Podemos, así, desgranar el carácter de geopolítica hidráulica que subyace detrás del concepto, pues se trata de analizar las relaciones internacionales a partir de la interacción entre la hidráulica, la política pública del agua y los resultados de ésta (Kauffer, 200 I, p. I60). Como afirma Elhance (2000), "el uso compartido de las aguas transfronterizas hace de la hidropolítica uno de los asuntos más urgentes, complejos y controvertidos que los países en desarrollo y la comunidad internacional tendrán que enfrentarse y resolver en el próximo siglo” (p. 202).

De especial interés resultan dos conceptos dentro del marco analítico de la hidropolítica. En primer lugar, la hidrohegemonía, entendida como el comportamiento, por parte de un estado ribereño de la cuenca de un río o de un complejo hídrico más amplio, tendente a preservar el status quo, protegiendo sus intereses y adoptando ciertos mecanismos de gestión de aguas transfronterizas a expensas de los otros estados ribereños, sea de manera voluntaria o forzada (Delgado y 
Teano, 2019, p. 98). En segundo lugar, la hidrodominación hace referencia a aquellas políticas destinadas a controlar los recursos de un río internacional o a utilizar estos recursos para controlar o presionar a los otros países ribereños, potenciando el liderazgo sobre los demás de una cuenca transfronteriza, aprovechando alguna combinación de posición geográfica, poderío militar, ventajas políticas y fuerza económica (Conde, 2017, p. 22).

En esencia, la hidropolítica pone de manifiesto que el control sobre los recursos hídricos no se consigue a través de las guerras del agua, sino mediante una estrategia ponderada de consecución de poder (Zeitoun y Warner, 2006, p. 436). Un hidrohegemón persigue la política de mantener el control sobre los recursos hídricos compartidos y minimiza cualquier intento de competencia por parte de los otros estados, mediante el uso de todos los medios necesarios y apaciguando los posibles conflictos, a menudo silenciados. El hidrohegemón ejerce su hegemonía para ser siempre la parte más beneficiada en un determinado contexto, en detrimento de los estados ribereños más débiles y desarrollando políticas agresivas de aprovechamiento de los recursos compartidos (Del Valle, 2017, p. 94). Las relaciones hídricas de China en el Himalaya se analizarán, por tanto, a partir de la consideración del agua como recurso que puede ser muy útil para la consecución de diferentes objetivos —económicos, políticos, sociales, culturales- y que puede llevar al gigante asiático a desarrollar políticas hidrohegemónicas y de hidrodominación (Conde, 20I7, p. I0).

\section{El Himalaya y las relaciones hídricas chinas}

La importancia estratégica del Himalaya es mayúscula, a nivel regional, continental y global, y por diferentes motivos. Este sistema montañoso se extiende a lo largo de ocho países -Afganistán, Bangladesh, Bután, China, India, Myanmar, Nepal y Pakistán- y se le considera la versión natural de la Gran Muralla China, dividiendo los dos países más poblados del mundo (Marshall, 20 I5, p. 46), que albergan un tercio de la población mundial pero poseen solo el $11 \%$ de los recursos hídricos globales (Chellaney, 20I I, p. 4).

El Himalaya es asimismo un tablero geopolítico de enorme importancia. En la segunda mitad del siglo $\mathrm{XX}$ los estados himalayos transformaron sus límites geográficos en fronteras políticas, y esta estatalización ha tenido consecuencias geopolíticas de calado (Murton, 2019, p. 8). $Y$ una de las ramificaciones es muy palpable en términos de las relaciones hídricas a nivel bilateral y regional. A lo largo de los 2400 kilómetros y de las diversas fronteras estatales que abarca el Himalaya, se solapan disputas de tipo político e histórico con consideraciones de carácter puramente hidrológico, lo que añade un tono más grisáceo al complejo panorama geopolítico del Himalaya. Empezando por la frontera entre India y Pakistán en la parte occidental, continuando por los problemas fronterizos entre China e India en la parte sureste del Himalaya y por la discutida frontera entre India y Nepal, y acabando en la parte más oriental por los límites fronterizos entre China y Nepal, así como la frontera entre China y Bután y disputas en la parte más oriental de las fronteras sino-indias. Se trata de disputas fronterizas que han ejemplificado el intento de los estados himalayos, y en esencia de Pakistán, China e India, de solidificar el control de este vasto territorio (Davis, Gamble, Roche y Gawne, 2020, p. 2). Y el acceso a los recursos hídricos es una pieza fundamental de este control. 
El hidropoder en el Himalaya

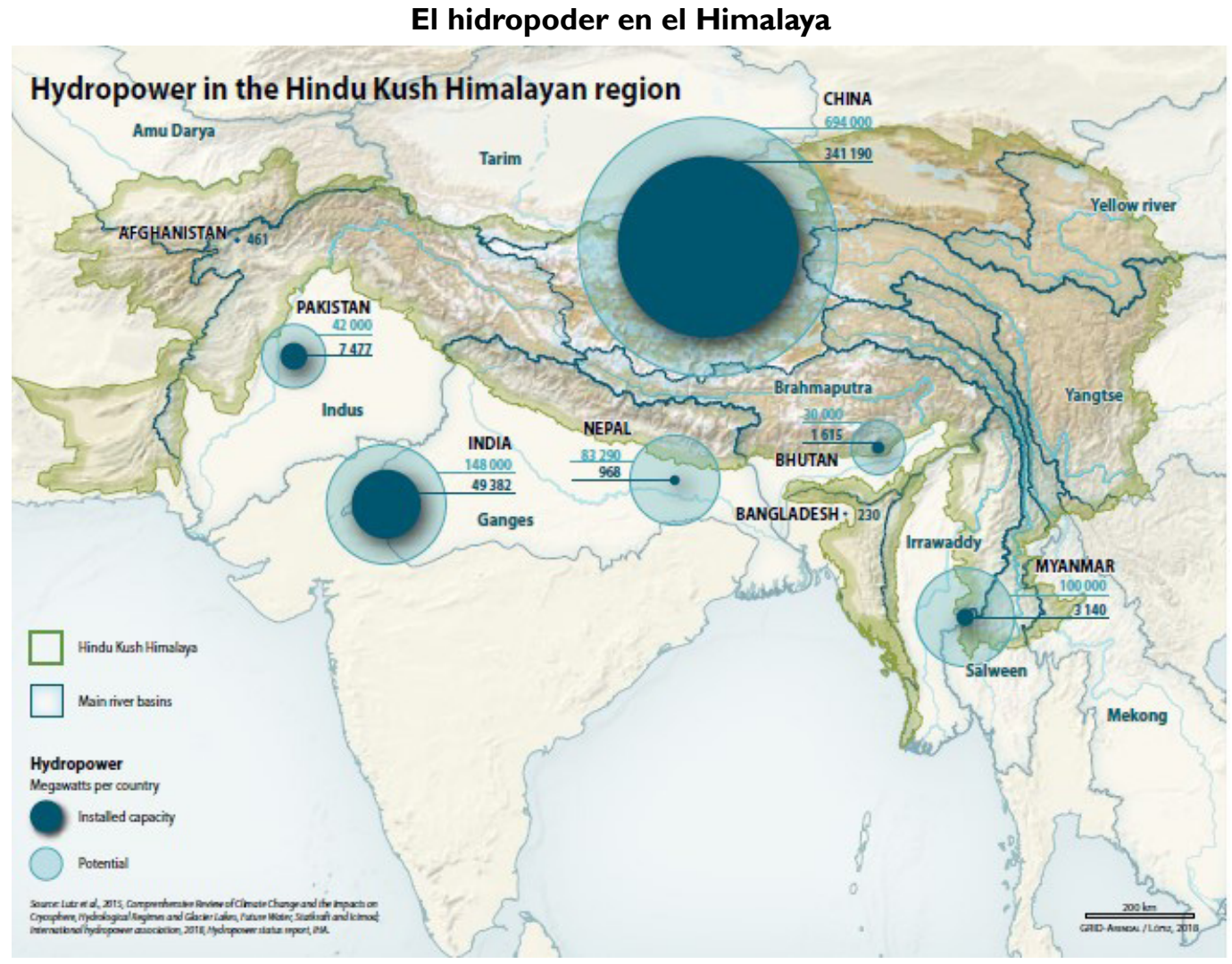

Fuente: Engelke y Michel, 2019

Se ha señalado anteriormente la importancia hídrica del sistema himalayo. ¿Qué factores externos e internos podemos señalar como determinantes del comportamiento hídrico chino en el Himalaya? ¿Hasta qué punto la estrategia de Pekín se puede catalogar de hidrodominación? Los dos casos que se estudian a continuación nos sirven para responder a estas preguntas.

\section{I. China y sus condicionantes internos: el Tíbet y la venganza de la geografía}

El punto de partida para el análisis de las relaciones con Nepal e India pasa, obligatoriamente, por la meseta tibetana. El Tíbet, y todo lo que representa para China, tiene un claro efecto colateral y evidentes ramificaciones internacionales. Con el $25 \%$ de la superficie del país, la meseta tibetana es una fuente casi inagotable de recursos de todo tipo, como bosques madereros, petróleo, gas natural, uranio, zinc, hierro, cobre y oro, aparte de energías geotérmicas y solares (Baños, 2019, P 129). La meseta tibetana constituye la puerta geográfica por la que China canaliza su flujo comercial hacia el exterior, y por la que accede parte de la energía que consume.

Pero el recurso más codiciado del Tíbet es el agua. Constituye el mayor reservorio de agua dulce del planeta, provee el $40 \%$ de los recursos hídricos chinos y representa dos tercios de la capacidad hidroeléctrica del país (Chellaney, 20I I, p. 95, p. I0I).Y es evidente por qué la política exterior de China y sus relaciones hidrológicas en la región del Himalaya, así como sus intereses estratégicos y de desarrollo, tienen en el Tíbet su epicentro. Los principales ríos del continente asiático nacen en las montañas tibetanas, siendo China el país aguas arriba para muchos estados asiáticos, con lo cual controla el suministro de agua de trece de sus países vecinos y tiene poder 
indirecto sobre las reservas hídricas de alrededor del $50 \%$ de la población mundial (Pomeranz, 20I3, p. 6). La meseta tibetana proporciona a China un control sobre el oro azul que convierte a China en un poder hídrico global, semejante al poder que el petróleo da a Arabia Saudí (Chellaney, 201 I, p. 105). Este escenario hídrico es de vital importancia para China, debido a la ventaja relativa que le otorga en comparación con el resto de los estados asiáticos: de ahí la importancia de analizar el caso del comportamiento hidráulico de China en el contexto himalayo.

\section{Ubicación del Tíbet y regiones fronterizas de la meseta tibetana}

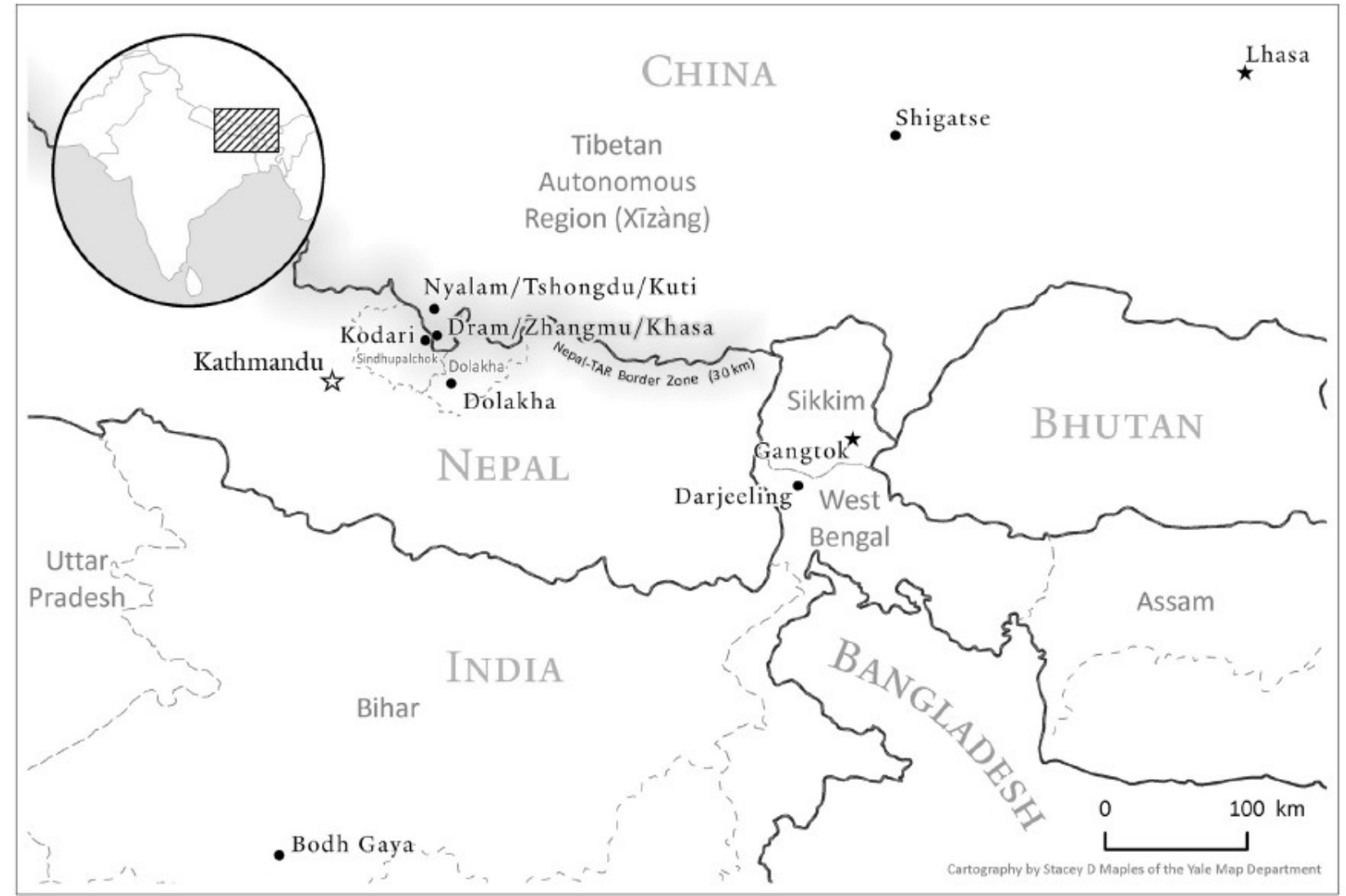

Fuente: Schneiderman, 20I3.

El segundo factor doméstico, de carácter geográfico y orográfico, es el flagrante desequilibrio hídrico chino puertas adentro. La geografía siempre importa. A diferencia de la cómoda posición geopolítica de otros gigantes mundiales, como Estados Unidos, China comparte fronteras terrestres con más de una docena de países, que ha conllevado numerosos conflictos transfronterizos (Jordán, 2018, p. 3l) y es el tercer país con el mayor número de ríos transfronterizos en el planeta. Pero debemos señalar que la disponibilidad de agua per cápita en el país más poblado le mundo se sitúa en un $25 \%$ de la media mundial, con lo que el gigante asiático se ve enfrentado casi de forma constante a una inminente crisis del agua ( $\mathrm{Li} \mathrm{y} \mathrm{Wu,} \mathrm{2017,} \mathrm{p.} \mathrm{60).} \mathrm{China} \mathrm{tiene} \mathrm{solo} \mathrm{el} \mathrm{6 \%} \mathrm{de}$ los suministros de agua dulce del planeta, que deben cubrir las necesidades de una quinta parte de los ciudadanos del mundo.

El desafío del agua en China se ve agravado asimismo por una situación muy desigual en el interior del país en cuanto a distribución espacial. El norte de China, que ocupa el $65 \%$ de 
la superficie terrestre del país y en el que vive el $45 \%$ de la población total, tiene solo el $17 \%$ del total de los recursos de agua dulce y sufre sequías periódicamente. Sin embargo, el sur del país contiene el $83 \%$ de los recursos de agua dulce del país para abastecer a cerca del $40 \%$ de la población, pero sufre más directamente los efectos de la climatología: durante la temporada de los monzones las fuertes lluvias con frecuencia causan inundaciones, con unas importantes consecuencias socioeconómicas (Zhang y Li, 2018, p. 699).

Este problema estructural, motivo permanente de preocupación por parte de las autoridades de Pekín, tiene consecuencias internacionales. El gobierno chino ha apostado como una posible solución a sus deficiencias hídricas por una mejor utilización de los grandes ríos que cruzan sus fronteras, con la consiguiente preocupación por parte de sus vecinos y la creciente presión a escala internacional para que Pekín revise su política de gestión de los recursos hídricos compartidos ( $\mathrm{Li}$ y Wu, 2017, p. 6I). La gestión interna de ríos como el Yangtzé en el sur o el Amarillo en el norte puede tener consecuencias regionales, ya que, si China apuesta por grandes proyectos hidráulicos que trasvasen el agua del sur al norte, en aprovechamiento de estos dos ríos que nacen en el Tíbet, ¿por qué no en el futuro hacer lo propio con los recursos de los países río abajo del Tíbet, como el Indo, el Ganges, el Mekong o el Brahmaputra? Es una preocupación evidente a escala regional.

Merece especial atención, en este sentido, el proyecto hidráulico en el que se embarcó el gobierno chino hace casi una década, el South-to-North Water Diversion Project, visualizado por Mao en 1952 y que empezó a cristalizar justo medio siglo después, en 2002 (Chellaney, 20II, p. 60). Este proyecto - el mayor y más ambicioso hasta la fecha de este tipo, doblando el presupuesto destinado a la presa de las Tres Gargantas - pretende ajustar el desequilibrio hídrico chino con grandes trasvases desde los ríos meridionales del país hacia las regiones y las grandes ciudades del este y el norte del país (Water Technology, 2020). Se trata de un megaproyecto que, según lo previsto, estará finalizado a mediados de siglo, y que plantea tres rutas principales para el desvío masivo de aguas hacia el nordeste del país: la central, la del este y la del oeste. Las dos primeras se iniciaron en 2013 y 20 I4, sin embargo, la ruta oeste ha quedado aplazada ya que debería realizarse en el Tíbet, en la cabecera de los dos ríos más importantes de China, el Yangtzé y el Amarillo, con consecuencias internacionales importantes, aunque se ha puesto como excusa la alta actividad sísmica de la zona, donde deben realizarse las obras (Rodríguez, 20 I8). Es evidente la repercusión de este proyecto para los vecinos de China, y como veremos a continuación, afecta directamente las relaciones diplomáticas con otros países, el más importante India. 


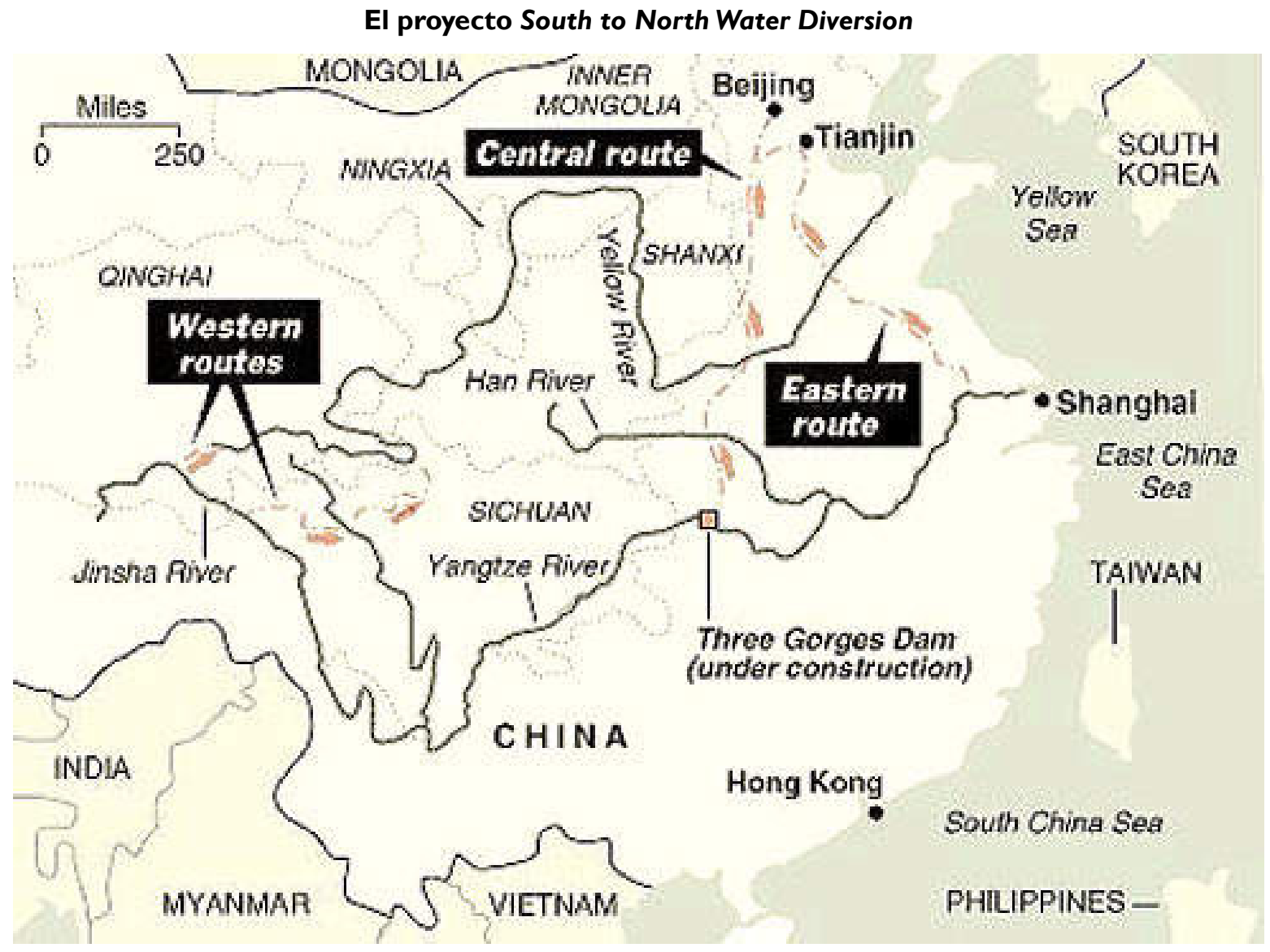

Fuente: https://www.water-technology.net/projects/south_north/

\subsection{China y Nepal, el apretón de manos himalayo}

El primero de los dos casos de estudio de la hidropolítica china en el Himalaya se refiere a las relaciones con Nepal. El país himalayo ha basculado en la última década entre su histórica relación con India y el reciente acercamiento a China, a partir del devastador terremoto de 2015, cuando China respondió con la mayor operación de su historia en cuanto a ayuda humanitaria, lo que llevó a reconfigurar las relaciones políticas, financieras e hidrológicas con el país himalayo, dando paso a la denominada diplomacia de las infraestructuras llevada a cabo por Pekín desde entonces (Murton y Lord, 2020, p. 2, 3). La presencia e influencia china en Nepal ha aumentado significativamente en los últimos años, siendo notable a todos los niveles, empezando por la fuerte presencia de ciudadanos tibetanos en Nepal y acabando por la peculiar caracterización de ciudadanos fronterizos que ambos países otorgan a los ciudadanos situados dentro de los 30 kilómetros de la frontera entre Nepal y el Tíbet (Schneiderman, 2013, p. 26). Esto nos da idea de la permeable visión sino-nepalí de la frontera común y de las relaciones bilaterales. Pero si hay un sector en el que las relaciones sino-nepalíes han avanzado en los últimos años, es sin duda las infraestructuras terrestres y los proyectos hidráulicos. Esta relación desarrollista entre Pekín y Katmandú se caracteriza por un fuerte componente de ayuda china para las infraestructuras nepalíes, incluyendo en especial la ayuda a grandes proyectos hidráulicos, y la intensificación del comercio transhimalayo, lo que llevado a los analistas a hablar del apretón de manos a través del Himalaya (Murton y Lord, 2020, p. I). 
Nepal es, hasta cierto punto, un laboratorio de la política hídrica china en el Himalaya. Este país es una ventana de oportunidad para China, por varias razones. China dicta las reglas del juego en cuanto a proyectos hidráulicos se refiere, lo que permite al gobierno chino ejercer una influencia notable sobre el aparto estatal nepalí. Además, la ubicación de Nepal es muy ventajosa para Pekín, por su orografía y su cercanía, atrae al complejo hídrico industrial chino, deseoso de nuevos espacios donde invertir. Este estado himalayo carece de la capacidad institucional y económica básica para poner en marcha proyectos hidráulicos de envergadura, debido a una combinación de obstáculos geográficos, burocráticos y geopolíticos (Murton, Lord y Beazley, 2016, p. 13). Y China ha sabido aprovechar de forma muy notable esta oportunidad, con ayuda logística y apoyo financiero a Nepal. Las numerosas inversiones en proyectos hidráulicos de Pekín han creado un nicho para el hidropoder y la hidrohegemonía china en el Himalaya, abriendo muchas posibilidades para proyectos e iniciativas en el marco de la iniciativa One Belt, One Road a partir del aprovechamiento de los pasillos de poder que Nepal representa en términos de interconexiones e infraestructuras. Se argumenta que la frontera sino-nepalí se expande y contrae todo lo necesario para favorecer la movilidad económica, religiosa y política (Schneiderman, 2013, p. 27).Y deberíamos añadir la movilidad hídrica.

Un caso destacable es el de la región nepalí de Rasuwa, con una fuerte presencia de refugiados tibetanos desde los años sesenta y en el que la infraestructura hidráulica, financiada por China, ha vertebrado cierto Tibetanismo en la región y ha ayudado a cimentar, aún más si cabe, las relaciones entre Pekín y Katmandú. Dicha región es primordial para la intención china de convertir Nepal en un corredor energético a través del Himalaya; tres de los nueves proyectos chinos en el marco de la BRI en Nepal se emplazan en Rasuwa, explicado en parte también por las ricas reservas minerales de la región (Murton y Lord, 20202, p. 7). China financia algunos proyectos de infraestructuras viarias, las cuales facilitan el acceso a y la interconexión de los proyectos hidráulicos. El más importante es la conexión por carretera entre dicha región y el territorio tibetano de Kyirong, donde diversas empresas chinas ya han mostrado interés en desarrollar numerosos proyectos (Murton, Lord y Beazley, 2016, p. 5). 
Infraestructura hídrica en Rasuwa (Nepal)

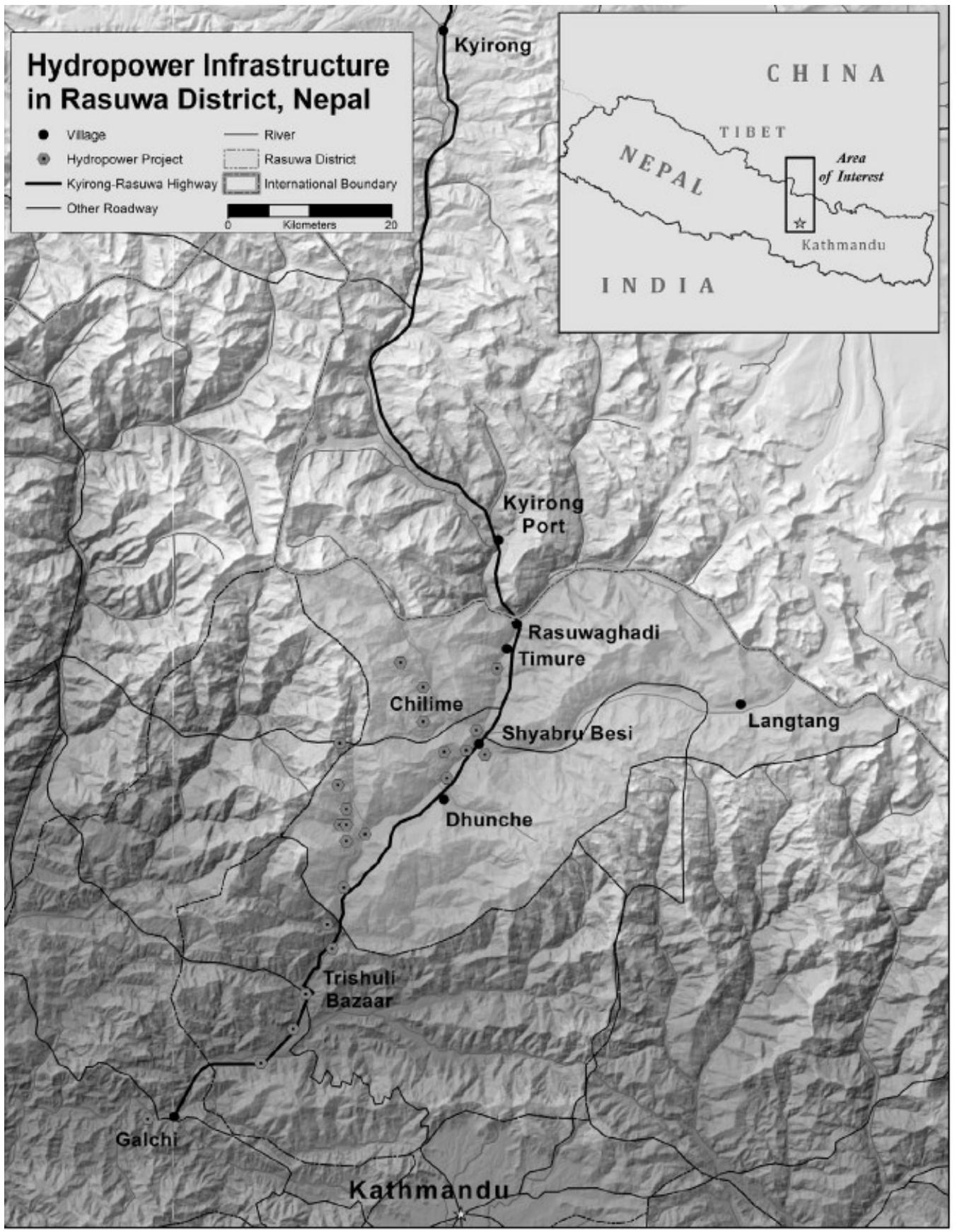

Fuente: Murton, 2016.

En otras palabras, la relación especial entre China y Nepal se caracteriza por el desarrollo del hidropoder y de los proyectos hidráulicos, principal sector de la inversión china y del state building en Nepal, así como la expansión de las redes de transporte e infraestructuras entre China y el sudeste asiático, lo que ha desembocado en un complejo sistema de proyectos chinos en Nepal bautizado como el regalo del desarrollo (Murton, Lord y Beazley, 20 I6, p. I0, p. II). La presencia hidráulica china en Nepal representa cierta forma de diplomacia de poder blando que aúna, por un lado, la falta de capacidad nepalí y el sueño de este país de convertirse en un estado con hidropoder con, por el otro, la hidrodominación china, centrada en el expansionismo fuera de 
su territorio (Lord, 20 I4, p. II7).

Un último apunte sobre las relaciones sino-nepalíes es la evidente asimetría del poder. Los proyectos hidráulicos no benefician igual a ambos países, ya que han privilegiado al país que ya contaba con un capital económico e hídrico suficiente, en aras de aprovecharse de nuevos corredores energéticos (Murton, 2019, p. 7). Observamos de nuevo como los factores externos - la expansionista política exterior china y sus proyectos a escala continental y global- nos explican la hidrodominación de la potencia asiática. El caso de Nepal ejemplifica que la estrategia China a nivel internacional tendrá éxito en la medida en que China consiga controlar las infraestructuras que desea, y esto en buena parte depende de que la balanza entre lo que un país obtiene y tiene que dar a China esté equilibrada. Algunos países con infraestructuras muy poco desarrolladas, como Nepal, pueden ver en la estrategia china un elemento atractivo, que puede ayudar a desarrollar su país y elevar el PIB (De Carlos, 2019, p. 19). En el caso de Nepal, la hidrohegemonía china va dando paso, poco a poco, a la hidrodominación de las infraestructuras hídricas del país. Será muy interesante analizar la estrategia china en otro tipo de estados con infraestructuras más consolidas o con menos asimetría en términos de poder.

\subsection{China e India, la hidropolítica de dos gigantes}

Las relaciones entre India y China se pueden catalogar como uno de los mayores antagonismos hidráulicos del planeta. Las tensiones entre Pekín y Nueva Delhi, históricamente, han tenido enormes repercusiones en la región Himalaya (Davis, Gamble, Roche y Gawne, 2020, p. 2). El estatus político del Tíbet y la delimitación de la frontera sino-india en la meseta tibetana siempre han sido un punto de fricción en la relación entre ambos países. Por otra parte, la anexión de India del pequeño reino de Sikkim en 1975 ha tenido efectos colaterales para la seguridad de Bután y de Nepal, y si añadimos Pakistán a esta ecuación, el conflicto por la región de Cachemira y la geopolítica de las potencias nucleares, se complica todavía más el panorama regional himalayo, que ha basculado históricamente al ritmo de las decisiones tomadas por China, India y Pakistán. Es destacable asimismo la posición de India como estado ribereño 'intermedio', ya que es el país aguas debajo de China, pero es el país aguas arriba de Pakistán y Bangladesh (Choudhary, Rai, Singh y Tiwari, 2015). Y tampoco es que India muestre un comportamiento muy cooperativo como estado aguas arriba: de los 57 ríos que entran en Bangladesh, 54 se originan en India, sin embargo, solo existe un acuerdo bilateral de gestión de aguas transfronterizas, en relación con el Ganges (Zhang, y Li, 20I8c, p. 7I2).

Es en este contexto de interdependencia compleja y de geopolítica global donde debemos enmarcar los dos episodios de las relaciones sino-indias que se presentan a continuación: la postura china en relación con el territorio del Sikkim y los proyectos hidráulicos chinos de construcción de grandes presas en el Brahmaputra. La región de Sikkim es uno de los últimos territorios que se incorporó a India, en los años setenta, y siempre ha sido un teatro para la confrontación entre China e India, ya que a las disputas fronterizas entre ambos países se suma la lucha por el aprovechamiento de los recursos hídricos (Huber, 2019, p. 17). China no reconoció Sikkim como estado indio hasta 2003, año en que India aceptó al Tíbet como región autónoma de China (Pardo, 2019, p. 5). El poder hidráulico de Sikkim seguirá siendo motivo de controversia entre Pekín y Nueva Delhi, y las ramificaciones ambientales de la explotación de estos recursos 
es una cuestión política, y pone de manifiesto la relación entre los recursos hídricos y otras cuestiones geopolíticas de la relación bilateral.

El otro caso significativo es la gestión del Brahmaputra, una de las principales arterias fluviales del continente asiático y el río transfronterizo más importante que nace en territorio chino, debido al volumen de transferencia de agua entre países y la importancia para los millones de personas que dependen de su irrigación (Chellaney, 20 I I, p. I43). El Brahmaputra es especialmente importante para India, ya que representa el 30\% de los recursos de agua dulce del país (Zhang, 20I5, p. I58) y el $40 \%$ de la capacidad de generación hidroeléctrica (Zhang y Li, 20I8c, p. 7I9).

El gobierno chino identificó al Brahmaputra como uno de los emplazamientos estratégicos clave para el desarrollo de energía hidroeléctrica (Ardi, 2008, p. 60), con la consiguiente preocupación por parte de Nueva Delhi. La gestión del Brahmaputra es un termómetro de las relaciones sinoindias y puede llegar a convertirse en un juego de suma cero, dada la importancia del río para ambos países y la tentación de ambos actores de usar una estrategia de planear-descuidar-reconstruir proyectos hidráulicos de gran envergadura (Pomeranz, 2013, p. 8). Recordemos que China ya se ha embarcado en megaproyectos hidráulicos usando las aguas del río, e India tiene muchos proyectos sobre la mesa. De hecho, India ha intensificado esfuerzos para contener la influencia china ante la creciente sensación de cerco a su patio trasero, es decir Nepal, Bután o Bangladesh (Pardo, 2019, p. I3).

\section{La cuenca del Brahmaputra.}

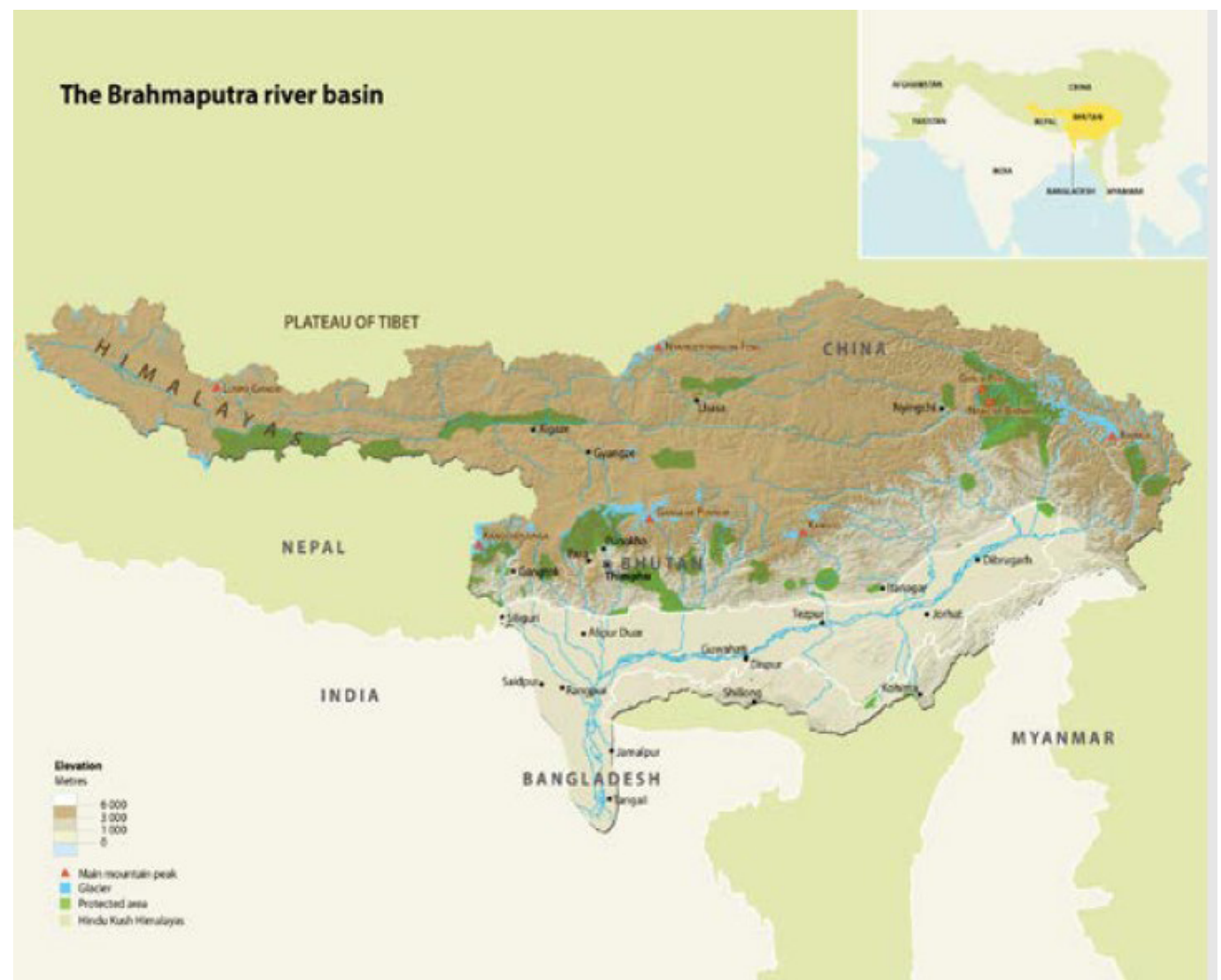

Fuente: Engelke y Michel, 2019. 
Los proyectos hidráulicos de Pekín se emplazan en el territorio limítrofe del Tíbet suroriental con la región la región india de Arunachal Pradesh — conocido como la cresta del Himalaya- y que Pekín históricamente ha reclamado, desde la independencia india del Reino Unido y el trazado de la Línea McMahon, como el Tíbet del Sur (Köpke, 2016). Este territorio ha añadido más tensiones a la ya complicada relación sino-india, y se suele señalar como uno de los factores más constrictivos de la cooperación bilateral en materia hidrológica (Zhang y Li, 2018c, p. 720).

El mayor punto de fricción ha sido el proyecto de la gran presa hidroeléctrica de Zamgmu en la llanura del Tíbet, en la denominada Gran Curva, que China finalmente consiguió empezar a construir después de numerosas negociaciones diplomáticas con India y Bangladesh. Nueva Delhi y Daca siempre mostraron notables reticencias a esta presa en las aguas superiores del Brahmaputra, ante el temor de que China pudiera afectar el curso del río aguas arribas a su paso por el Tíbet o construir nuevas presas en ese caudal, que podrían interrumpir el suministro de agua río abajo (Roca, 2015). India ve con mucho recelo la construcción de esta presa, pero sobre todo concibe como una amenaza directa la posibilidad de que en el futuro China pueda desviar el curso del río Brahmaputra hacia arriba, como parte de su megaproyecto de irrigar el norte del país a partir de los recursos hídricos de este río (Engelke y Michel, 2019, p. 28). La hegemonía hídrica y el comportamiento de dominación chino están muy presentes en los cálculos geopolíticos de Nueva Delhi, debido a la dependencia india del agua rio abajo y la consiguiente vulnerabilidad ante el potencial uso de China del agua como instrumento político (Chellaney, 20I I, p. I43). El Brahmaputra es, ciertamente, un elemento más de la securitización de las relaciones entre China e India.

Las relaciones hídricas entre China e India tienen un trasfondo geopolítico mayor, relacionado con el Tíbet, que reviste una gran importancia religiosa y cultural para India, sin mencionar la importancia geopolítica del territorio (IDSA, 20I2, p. I2). La forma en que China ha utilizado la meseta tibetana se ha interpretado como un toque de atención por parte del gigante asiático hacia su vecino hindú, que demuestra quién manda en Asia (Arpi, 2008, p. 58). Controlar el Tíbet significa controlar el acceso a la China interior desde el subcontinente indio y el control aguas arriba de los tres ríos más importantes para China. Y Pekín no va a permitir el menor atisbo serio de control, dominación o presencia india en el Tíbet. Y de ahí también el ritmo con el que se acometen los proyectos chinos de construcción de carreteras y ferrocarril a través del macizo tibetano (Kaplan, 20I4, p. 26I). Y el proyecto de divertir aguas desde el Tíbet hacia el norte del país simboliza también el permanente afán chino de basar su desarrollo en una política de infraestructuras expansiva, con grandes obras faraónicas que sigan demostrando la preponderancia de Pekín (Chellaney, 20II, p. 7I).

El comportamiento chino de hidrodominación, basado en la posesión de los recursos de esta meseta, pone de manifiesto que la geopolítica del miedo ha jugado un papel primordial. China siempre ha querido demostrar su dominio en el Tíbet a ojos de India, evitando cualquier intento de control indio del territorio tibetano o de acceso a los recursos hídricos del territorio (Marshall, 2015, p. 47).Y aquí podemos destacar el concepto clásico de soberanía, elemento vertebrador de las relaciones internacionales y pieza fundamental para China en el teatro hidropolítico himalayo, ya que el uso y gestión de los recursos hídricos transfronterizos está directamente relacionada 
con la soberanía estatal (Choudhary, Rai, Singh y Tiwari, 20I5).

\section{A modo de análisis; factores externos e internos, y estrategia global de China}

China se siente fuerte en el panorama internacional actual: se siente fuerte en un contexto regional marcado por la falta de cooperación internacional o integración regional, y se siente aún más fuerte en un contexto internacional complejo y que pasa por la crisis del multilateralismo: podemos afirmar que la hidrohegemonía de Pekín es un factor desequilibrante de primera magnitud. El foco de los proyectos hidráulicos chinos de construcción de presas y diversión de los cauces de los ríos puede saltar las fronteras del país y trasladarse a los grandes ríos trasfronterizos del continente, megaproyectos que se ubican en territorios con gran carga geopolítica, sea por las disputas bilaterales o regionales, por la posesión de recursos naturales o por la presencia de importantes minorías étnicas (Chellaney, 20II, p. 3). Cualquier movimiento hídrico de China puede tener consecuencias de calado en su periferia $y$, como consecuencia, a nivel continental y global. Los casos de Nepal y de India ilustran la hidrohegemonía china en el Himalaya y su estrategia de hidrodominación. ¿Qué factores externos e internos podemos señalar? ¿Qué estrategia hidropolítica ha seguido el gobierno chino?

El primer factor explicativo es la forma en que China utiliza los valiosos recursos que le proporciona la meseta tibetana para imponer las reglas del juego en términos hidráulicos en el Himalaya. Contener el $30 \%$ del agua dulce de toda Asia y ser el origen de los ríos que abastecen a la mitad de la población mundial es un factor de poder de proporciones globales. El Tíbet no solo es el punto neurálgico de la rivalidad geopolítica, económica e hidrológica entre China e India, sino que dominar esta región permite a China ejercer una posición de privilegio sobre un arco de países que extiende desde Pakistán a Vietnam. Es decir, la hidrohegemonía.Y por eso los planes chinos de embalsar o desviar algunos cursos fluviales en dirección a las principales ciudades chinas han puesto en máxima alerta a los países vecinos (Baños, 2019, p. 169). Es decir, la hidrodominación.

Un segundo factor es la transformación de China en una potencia global, que ha generado una búsqueda incesante de fuentes de energía, materias primas y otros recursos para sostener el crecimiento económico. Y no olvidemos las necesidades imperiosas de consumo de agua de China, su fuerte crecimiento demográfico y sus desequilibrios hídricos. Pekín ha basado parte de su estrategia en posicionarse mejor que el resto de los jugadores en el tablero de los recursos globales (Rogers y Crow Miller, 2017, p. 5), y la hidrohegemonía en el Himalaya y los episodios de hidrodominación son muestra de ello. China se puede considerar la única potencia regional cuyo poder tiene alcance global (Espinoza, 20I7, p. 245) y que, de los llamados BRICS, el único miembro del bloque con capacidades materiales para ejercer el papel de potencia global sigue siendo China (Mouron, Urdinez y Schenoni, 2016, p. 19). La política hídrica de China y su relación con el resto de estados himalayos debe analizarse en conjunción con la ascensión del gigante asiático a escala global en las dos últimas décadas, y el hecho de que hoy en día ya no sea una superpotencia emergente (Kelly, 2018, p. II0). China es el país del mundo que cuenta con un mayor número de presas hidráulicas, lo que refleja el continuismo de la política maoísta de cuanto más grande, mejor (Chellaney, 20I I, p. 6I).

Un tercer factor es el estilo chino de política exterior. Es reseñable la ausencia, o la apatía, 
de China en organismos o fotos multilaterales de gestión de los recursos hídricos compartidos, y la apuesta de Pekín por un modelo basado en relaciones informales, preferentemente bilaterales y con una fuerte carga de opacidad (Yuan, 2018, p. 78). A esto añadimos la tendencia china a no consultar a ningún estado riberano antes de iniciar algún movimiento que afecte las aguas transfronterizas (Hukil, 2013) y la preferencia por las soluciones bilaterales o a la carta para problemas complejos, antes que apostar por marcos decisionales de cariz multilateral y con fuerza legal, que puedan minar su soberanía en relación con la gestión de los ríos transfronterizos (Wu y Li, 20I7, p. 67).

Se habla incluso de hidroarrogancia e hidroegoismo por parte de China. Es significativo que China, de facto, nunca se haya comprometido con ningún tratado de gestión de aguas ribereñas, siendo uno de los tres países que no ha ratificado la Convención de Naciones Unidas de 1997 sobre el derecho de los usos de los cursos de aguas internacionales para fines distintos de la navegación (Delgado y Teano, 2019, p. 102). El avance chino y su casi indisposición a cooperar o consultar a los países río abajo, crea una permanente sensación de preocupación en el resto de estados de la región (Engelke y Michael, 2019, p. 26). El contexto internacional actual también debe señalarse como un factor de peso: el tradicional oportunismo chino se ve plasmado en el uso, de forma muy inteligente, del impulso inicial de la UNESCO del proyecto de la nueva ruta de la seda y apropiárselo, lanzándose a una carrera de inversiones en infraestructuras y megaproyectos hidráulicos por todo el mundo. Igualmente, el bilateralismo típico de las épocas de crisis del sistema internacional juega a favor de Pekín (De Carlos, 2019, p. 7).

Otro ejemplo de la hidrodominación china es la gobernanza del Mekong. La ausencia de Pekín en la Comisión Internacional de gestión de este río aboca a este organismo al fracaso o la ineficacia. China no concibe tratar sus proyectos de construcción de presas río arriba en esta Comisión, con la consecuente preocupación de los países río abajo (Jiménez, 2019, p. 50). Podríamos destacar igualmente el hecho de que China haya firmado trece acuerdos bilaterales de gestión hídrica con Rusia y once con Corea del Norte, pero solo dos con Vietnam e India (Li yWu, 2017, p. 63).

En el caso de Nepal, China sigue una estrategia de dar pequeños pasos en este país y poco a poco ir hidrodominando este país, apoyándose en una doble estrategia de la diplomacia de las infraestructuras y de diluir la relación bilateral entre Nepal e India. El caso de India es mucho más complejo, ya que entran en juego, aparte de las consideraciones anteriormente expresadas, la rivalidad histórica entre ambas naciones y una relación de desconfianza mutua, el nacionalismo creciente de ambos estados, el secretismo en sus relaciones bilaterales y la ausencia de foros de negociación multilateral (Barua, Vij y Zulfiqur, 2018, p. 835).

Sin llegar al extremo de hablar de las guerras del agua entre ambos países, sí que debemos señalar el carácter absolutamente politizado de las relaciones hídricas entre ambos actores (Chellaney, 2013). India y China no tienen ningún acuerdo bilateral integral de gestión del Brahmaputra o de resolución de posibles contenciosos al respecto, lo que deja un amplio margen de maniobra para la bilateralidad, la informalidad y la vulnerabilidad antes consideraciones políticas y estratégicas de tipo coyuntural. Es notorio que en los últimos veinte años Pekín y Nueva Delhi hayan suscrito cuatro Memorandos de Entendimiento bilaterales, pero solo dos de 
ellos en relación con la gestión de los recursos hídricos transfronterizos, limitados al intercambio de información y datos, y que deben ser renovados de forma anual (Engelke y Michel, 2019, p. 22). Por tanto, la gestión compartida de los recursos hídricos entre Pekín y Nueva Delhi siempre está a expensas de la situación geopolítica de cada momento y carece de estabilidad.

El enfoque bilateral que ambos estados han adoptado en relación con el Brahmaputra ha creado cierto sentimiento de control unilateral sobre la cuenca del río, que se ha traducido en la ausencia de un marco multilateral de gestión de los recursos hídricos compartidos y en el sentimiento de exclusión, más que notable, de los otros estados ribereños (Zhang y Li, 20l8b, p. 703). Varios analistas señalan que la política china hacia India, a diferencia del caso de Nepal o de otros estados, se ha basado en los criterios de buena vecindad y no intervención, con un comportamiento reactivo y ciñendo la cooperación bilateral al intercambio de información y datos sobre la gestión de las aguas transfronterizas (Marsden y Brandon, 2015). Esto ejemplifica que la política exterior hídrica de China va más allá del tradicional binomio conflicto vs cooperación, ya que la inacción y la apatía parecen cristalizar a nivel de estrategia china en relación con la gestión de los ríos transfronterizos y las relaciones con los países aguas abajo.

\section{Los grandes ríos asiáticos.}

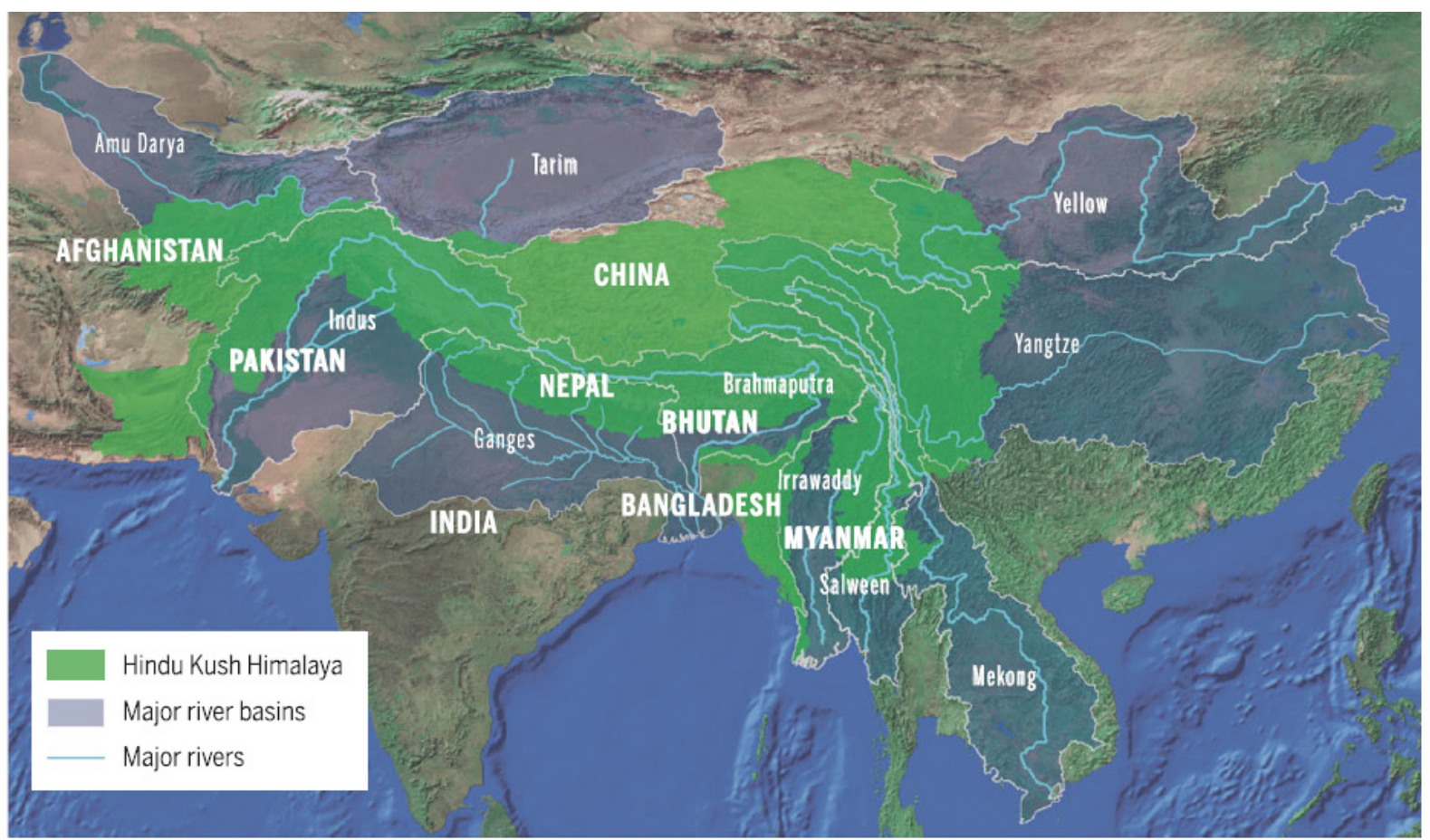

Fuente: Hindu Kush Himalaya Assessment, 2019

La estrategia china en términos hidrológicos empieza por el Tíbet, ya que Pekín intenta convertir esta región en un corredor estratégico con la región central y sur asiática, consolidando el comercio transhimalayo y las relaciones transfronterizas del Tíbet, y desarrollando numerosos proyectos hidráulicos. Y continua por desarrollar grandes proyectos en las fronteras fluviales del Himalaya oriental, que puede también interpretarse como una lucha de poder a lo largo de las grandes cuencas transfronterizas (Zhang y Li, 2018, p. 699). 
La ambivalencia de China como estado hidráulico — desequilibrios y escasez hídrica a nivel doméstico, hegemonía a nivel internacional - es seguramente el punto de partida de la estrategia hidropolítica china y su apuesta por el expansionismo exterior. La hidrodominación china no puede disociarse de la estrategia de Pekín de posicionamiento como gran potencia, a nivel regional, continental y global, en diversos ámbitos. En los últimos años, China ha pasado de estar volcada hacia el interior y a la expectativa en sus relaciones internacionales, a llevar a cabo una política exterior expansionista e intentar lograr el sueño chino de ocupar un lugar central en el mundo. Es evidente que la diplomacia china conjuga ahora mejor que nunca sus intereses económicos, geoestratégicos y de seguridad (De Carlos, 2019, p. 3).

Pekín ha apostado claramente por mantener un papel pasivo, secundario, a la hora de afrontar con sus vecinos la gestión de los sistemas internacionales hidráulicos enAsia. China apuesta por el unilateralismo, sigue imponiendo su hidrohegemonía, que se traduce en la construcción, no solo en el Himalaya sino también en la parte más oriental de Asia, de diversas infraestructuras hidráulicas de forma unilateral, sin diálogo con sus vecinos y sin ciertos mecanismos de gobernanza hídrica regional.

En definitiva, la estrategia china consiste en la reafirmación de su hegemonía hídrica no solo en el Himalaya, sino también en Asia, basada en cierto imperativo estratégico que apuesta por la dominación antes que por la cooperación. Una vez más, los conceptos de hidrohegemonía e hidrodominación nos ayudan a entender las relaciones exteriores de la potencia asiática.

\section{Conclusión}

El presente artículo tenía como punto de partida analizar el comportamiento hidráulico chino en el enclave estratégico del Himalaya, a la luz del marco conceptual de la hidropolítica. Dos pinceladas principales cierran el presente artículo. Las relaciones hidrológicas del gigante asiático deben entenderse más por el contexto de lucha global por los recursos, y considerando la ambiciosa estrategia china de consolidación como potencia global, que por un mero cálculo hidropolítico de gestión compartida de los recursos hídricos en el Himalaya. En el caso de China, la diplomacia hídrica, en el sentido más amplio del término, es bastante deficitaria, al contrario que la hidrohegemonía y la hidrodominación, que caracterizan la política exterior china en las relaciones hídricas a nivel internacional.

Analizar las tendencias geopolíticas globales nos ayuda a enfocar mejor la hidropolítica china. China ha sabido explotar su hidrohegemonía con una estrategia decidida y expansiva, orientada a controlar las infraestructuras hidráulicas necesarias para asegurar su comercio y sus planes económicos (De Carlos, 2019, p. 19) e intentando ocupar el mayor número de emplazamientos estratégicos clave. Pekín ha ejercido una política decidida de hidrodominación y, en gran medida, ha impuesto su agenda hidráulica al resto de países de la región. El comportamiento hidráulico chino debe entenderse como una arista más de las relaciones políticas bilaterales y regionales de la potencia asiática, y cómo Pekín gestiona río arriba los ríos transfronterizos debe entenderse como una parte integral del marco general de las relaciones bilaterales de Pekín con cada estado ribereño (Li y Wu, 20I7, p. 64). 
En segundo lugar, se puede afirmar que China ha seguido un comportamiento paradigmático en su condición de hidrohegemón, al basar su preponderancia no solo en su posición de estado ribereño aguas arriba para la mayoría de países de la región, sino sobre todo por imponer su poder político y económico al resto de actores del mismo complejo. Suele afirmarse que los países río arriba suelen utilizar el agua para conseguir más poder, mientas que los países río abajo usan el poder para conseguir más agua (Barua,Vij y Zulfiqur, 2018, p. 830). Y Pekín ha sido capaz de sedimentar un discurso particular a nivel regional, e incluso global, globalizando una cierta idea de la gestión transfronteriza del agua que favorece, muy claramente, sus intereses. China es una potencia ultrarealista, necesita estabilidad, no virtud, y satisfacer sus necesidades económicas tiene un impacto global (Kaplan, 20I4, p. 254). China quiere demostrar su autoridad al mundo, quiere reafirmarse como potencia global, quiere ser cada día más asertiva y, seguramente, necesita diversificar y ampliar la agenda de países con los que negocia para el aprovisionamiento de recursos naturales y materias primas. $Y$ es esta dimensión la que nos subraya cómo China usa su poder hidrohegemónico en el Himalaya.

El auge de China en el contexto internacional actual se ha cimentado en un contexto de Westlessness y de una tremenda crisis del multilateralismo, y en el que Pekín ha sabido posicionarse con un modelo de gobernanza alternativo al occidental y bordeando, en la medida de lo posible, las regulaciones legales supranacionales y cuando puede las nacionales (De Carlos, 2019, p. 14). La diplomacia china se inclina por soluciones bilaterales, en general canalizadas a través de su iniciativa de la One Belt, One Road, a lo que debemos sumar la opacidad de la política exterior china (Engelke y Michel, 2019, p. 4). Es notable la falta de liderazgo chino en foros multilaterales en lo que se refiere a la gestión hidráulica, así como la ausencia, tanto formal como informal, en organismos multilaterales o convenciones internacionales legalmente vinculantes en asuntos de aguas transfronterizas ( $\mathrm{Li} \mathrm{y} \mathrm{Wu,} \mathrm{2017,} \mathrm{p.} \mathrm{68).} \mathrm{Esto} \mathrm{genera} \mathrm{un} \mathrm{clima} \mathrm{de} \mathrm{incertidumbre} \mathrm{no} \mathrm{solo}$ regional, sino seguramente global, en lo referido a la política hidráulica de China.

El estudio de los casos de Nepal e India ejemplifica que la posesión de recursos naturales es una herramienta de inestimable valor y alcance geoestratégico, la cual puede ser utilizada con el legítimo objetivo de tratar de equilibrar la balanza geopolítica (Espinoza, 20I 9, p. 252). En términos hidropolíticos, podemos afirmar que el agua representa para Pekín un recurso asimétrico de poder no solo en el complejo del Himalaya, sino seguramente a nivel continental y global. ¿Por qué? China controla, en primer lugar, el suministro de agua de muchos de sus países vecinos $y$, en segundo, tiene acceso directo a las reservas hídricas de agua dulce de alrededor de la mitad de la población mundial.Y no podemos olvidar el escenario actual de competición por los recursos a escala global e interdependencia económica, así como los problemas de suministro hídrico del gigante asiático, su creciente industrialización y su demografía. El caso de China y el Himalaya demuestra las ramificaciones a escala internacional de los asuntos domésticos; con lo cual el problema hídrico chino es un asunto geopolítico global.

\section{Referencias}

Administración Central del Tíbet (2020), Tibet at a Glance https://tibet.net/about-tibet/tibet-at-a-glance/ (Último acceso 25.05.2020)

Ancel, J. (2016). La geografía de las fronteras. El método. Geopolítica(s), 7 (I), I 3 | - | 42.

Arpi, C. (2008). Himalayan Rivers. Geopolitics and Strategic Perspectives. Indian Defence Review, 23 (2), 56-65. 
Baños, P. (20I9). El dominio mundial. Elementos del poder y claves geopolíticas. Barcelona: Planeta.

Barua,A.,Vij, S.y Zulfiqur, M. (2018). Powering or sharing water in the Brahmaputra River basin. International Journal of Water Resources Development, 34 (5), 829-843.

Biagi, M. Fermoselle,A. y Ferro, M. (20I4). Hidropolítica; los caos de Brasil y Argentina. Escuela de Guerra Naval,Armada Argentina, 60, 73-85.

Blanco, F. (20I7). Los recursos hídricos en el mundo: cuantificación y distribución. El agua: ¿fuente de cooperación o de conflicto? Instituto Español de Estudios Estratégicos. Cuaderno de Estrategia, I 86, 2 I-70.

Brito,A. y Missio, F. (2019). Regulação e hidropolítica na fronteira Brasil-Paraguai. Desenvolvimiento e Meio Ambiente, 52, 2 I-47, DOI: 10.5380/dma.v52i0.65310.

Burgos, S. y Ear, S. (2012). The Geopolitics of China's Global Resources Quest. Geopolitics, 17, 47-79, DOI: 10.1080/14650045.2011.562943.

Candela, L. y Fernández-Jáuregui, C. (1999). Prefacio. Agua y Desarrollo. Revista CIDOB d’Afers Internacionals, 45-46, 7- I0.

Chellaney, B. (20I I). Water. Asia's New Battleground. Washington: Georgetown University Press.

Chellaney, B. (23.04.2013). China's New War Front: Natural Resource as a Political Tool. Times of India. Disponible en https://timesofindia.indiatimes.com/edit-page/Chinas-new-war-front-Natural-resource-as-a-political-tool/ articleshow/ / 9683339.cms. (28.09.2020).

Chellaney, B. (2009). Evitar las guerras del agua. La Vanguardia, 04.1 I.2009.

Choudary, R., Rai, S., Singh, P. y Tiwari, H. (20I5). Hydropolitics between India - China: status vs Perspectives. Trabajo presentado en el Hydro 2015 International, $20^{\text {th }}$ International Conference on Hydraulics, Roorkee.

Conde, G. (2017). Agua, poder y hegemonía entre actores estatales y no estatales en Turquía, Siria e Iraq. Estudios de Asia y África, 52, I (162), 5-28.

Davis,A., Gamble, R., Roche, G.y Gawne, L. (2020). International Relations AndThe Himalaya: Connecting Ecologies, Cultures And Geopolitics. Australian Journal of International Affairs, I-2 I. DOI : 10.1080/10357718.2020. 1787333.

Daoudy, M. (2009). Asymmetric Power: Negotiating Water in the Euphrates and Tigris. International Negotiation, I4, $36 \mid-391$.

De Carlos, J. (2019). La estrategia global de china para defender sus intereses. Instituto Español de Estudios Estratégicos. Documento de Opinión, 4, 1-23.

Delgado J.y Teano, F.(2019). El concepto de hidrohegemonía como marco de análisis de los conflictos transfronterizos por el agua. Pensando en el caso Chino. Agua y Territorio, I4, 97-I04. DOI 10.1756 I/at. I4.4437.

Del Valle, J. (20I7). El agua, un recurso cada vez más estratégico. El agua: ¿fuente de cooperación o de conflicto?, Instituto Español de Estudios Estratégicos. Cuaderno de Estrategia, 186, 7I-II7.

Elhance, A. (1999). Hydropolitics in the Third World. Conflict and Cooperation in International River Basins. Washington: United States Institute of Peace Press.

Elhance, A. (2000). Hydropolitics: Grounds for Despair, Reasons for Hope. International Negotiation, 5, 20 I-222.

Engelke, P. y Michel, D. (2019). Ecology meets Geopolitics. Water Security in Himalayan Asia. Washington DC: Atlantic Council.

Espinoza, E. (2019). Los recursos naturales son poder: la geopolítica de las periferias latinoamericanas durante el boom de precios de materias primas y el ascenso económico de China. Geopolítica(s), 10 (2), 229-258, https://dx.doi.org/10.5209/geop.66399

Fernández-Jáuregui, C. (2017). Introducción. El agua: ¿fuente de cooperación o de conflicto?, Instituto Español de Estudios Estratégicos. Cuaderno de Estrategia, 186, I3-19.

Fernández-Jáuregui, C. (1999). El agua como fuente de conflictos: repaso de los focos de conflictos en el mundo. Agua y Desarrollo. Revista CIDOB d'Afers Internacionals, 45-46, I79-194.

Fundación Casa del Tíbet (2020). Historia del Tíbet. https://www.casadeltibetbcn.org/es/la-casa-del-tibet/el-tibet (I6.04.2020).

Huber,A. (2019). Hydropower in the Himalayan Hazardscape: Strategic Ignorance and the Production of Unequal Risk. Water, I (4 I4). DOI: I0.3390/w I I0304I4

Hukil, R. (9.05.2013). India, China and the Brahmaputra: Understanding the Hydro-Politics. Institute of Peace and Conflict Studies. Recuperado de: http://www.ipcs.org/comm_select.php?articleNo=3925. (27.09.2020).

Institute for Defence Studies and Analyses (2012). Tibet and India's security: Himalayan region, refugees and SinoIndian relations. IDSA Task Force Report.

Jiménez, T. (2009). La cuestión del agua. Medio ambiente, cambio climático y conflictos internacionales. Barcelona: Universidad de Barcelona.

Jordán, J. (2018). Un modelo de análisis geopolítico para el estudio de las relaciones internacionales. Instituto Español de Estudios Estratégicos. Documento Marco 04, I-44.

Julien, F. (20/2). Hydropolitics is What Societies Make of It (or Why We Need a Constructivist Approach to the Geopolitics of Water). International Journal of Sustainable Society, 4, I-2, 45-7I.

Kaplan, R. (20I4). La venganza de la geografia. Cómo los mapas condicionan el destino de las naciones. Barcelona: RBA.

Kauffer, E. (20II). Hidropolíticas en la frontera entre México, Guatemala y Belice: la necesaria redefinición de un concepto para analizar la complejidad de las relaciones en torno al agua en escenarios transfronterizos. Aqua-LAC, 3 (I), I57-I66.

Kehl, J.R. (20II), Hydropolitical Complexes and Asymmetrical Power. Conflict, Cooperation and Governance of International River Systems, Journal of World-Systems Research, 17 (I), 218-235. https://doi.org/I0.5/95/ 
jwsr.20II.429

Kelly P. (2018). The United States and the geopolitics of water: human need, Mississippi river barges, and offshore Eurasian balancing. Geopolitics, History, and International Relations, I0 (I), 94-I I 8, DOI: I 0.2238 I/GHIR I0I 20 I85

Köpke, S. (marzo, 2016). The Hydropolitics of the Brahmaputra:A Political Ecology of Water, comunicación presentada en Undisciplined Environments, Estocolmo.

La Vanguardia (20I5). La gran presa china en el Tíbet funciona desde hoy a pleno rendimiento (13.10.20I5) Recuperado de: https://www.lavanguardia.com/economia/20151013/54437/96014/la-gran-presa-china-enel-tibet-funciona-desde-hoy-a-pleno-rendimiento.html

$\mathrm{Li}$, Z. yWu, F. (20I7). China and shared water resources: geopolitics, domestic institutions and global Governance. En Wu, F.y Zhang, H. (Eds.). China's Global Quest for Resources. Energy, Food and Water (59-78). Oxon: Routledge.

López Trigal, L. (2016). La cuestión geográfica del Estado-nación y la 'frontera natural'. Geopolítica(s), 7 (I), I43-I5I. DOI http://dx.doi.org/10.5209/rev_GEOP.2016.v7.nI.52955

Lord,A. (20I4). Making a 'Hydropower Nation': Subjectivity, Mobility, and Work in the Nepalese Hydroscape. Himalaya, Journal of the Association for Nepal and Himalayan Studies, 34, I I - I 2 I.

Martínez, R. (2014). ¿Por qué China se empecina en invadir el Tíbet? El Confidencial, https://www.elconfidencial.com/ mundo/2009-10-10/por-que-china-se-empecina-en-ocupar-el-tibet_244828/ (I8.03.2020).

Mackinder, J. (1904). The Geographical Pivot of History. Conferencia pronunciada ante la Royal Geographical Society, Londres. Reproducida en The Geographical Journal, 23 (4), 42 I-437.

Marsden, S, y Brandon, E. (20I5). Transboundary Environmental Governance in Asia: Practice and Prospects with UNECE Agreements. Cheltenham: Edward Elgar Publishing.

Marshall, T. (20I5). Prisoners of Geography. Ten Maps That Explain Everything About The World. Nueva York: Elliot and Thompson Limited.

Mgquba, S. y Majozi, S. (2020). Climate change and its impacts on hydro-politics in transboundary basins: a case study of the Orange-Senqu River basin, Journal of Water and Climate Change, II (I), I50-I65. DOI: I0.2 I66/ wcc.2018.166

Mouron, F., Urdinez, F. y Schenoni, L. (2016). Sin espacio para todos: China y la competencia por el Sur. Revista CIDOB d’Afers Internacionals, II4, 17-39.

Murton, G. (2016). Making Mountain Places into State Spaces: Infrastructure, Consumption, and Territorial Practice in a Himalayan Borderland. Annals of the American Association of Geographers, I-10. DOI: 10.1080/24694452.2016.123216

Murton, G. (2019). Facing the fence: The production and performance of a Himalayan border in global contexts. Political Geography, 72, I- 12.

Murton, G., Lord, A. y Beazley, R. (2016). "A handshake across the Himalayas:” Chinese investment, hydropower development, and state formation in Nepal. Eurasian Geography and Economics, I-3I. DOI: 10.1080/I5387216.2016.1236349

Murton, G. y Lord, A. (2020). Trans-Himalayan power corridors: Infrastructural politics and China's Belt and Road Initiative in Nepal. Political Geography, 77, I-I3.

Pardo, J. (2019). El conflicto fronterizo entre India y China, Doklam. Implicaciones geoestratégicas. Instituto Español de Estudios Estratégicos. Documento de Opinión, 38, I- I5.

Pérez Martín, M. (20I3). Recursos hídricos y organizaciones multilaterales de seguridad en Asia Central. Revista CIDOB d’Afers Internacionals, I0I, I29-I50.

Pomeranz, K. (20I3).Asia's Unstable Water Tower:The Politics, Economics, and Ecology of Himalayan Water Projects. Asia Policy, I0 (I6), 4-I0. https://doi.org//0.1353/asp.2013.0023

Programa de las Naciones Unidas para el Desarrollo (2006), Más allá de la escasez: poder, pobreza y la crisis mundial del agua, http://hdr.undp.org/sites/default/files/hdr_2006_es_completo.pdf

Programa de las Naciones Unidas para el Desarrollo (2016), Desarrollo Humano Para Todos, http://hdr.undp.org/ sites/default/files/HDR2016 SP Overview Web 0.pdf

Programa de las Naciones Unidas para el Medio Ämbiente (2007), Vulnerabilidad y Resistencia Hidropolíticas en Aguas Internacionales. América Latina y el Caribe, I- I33. Recuperado de: http://wedocs.unep.org/bitstream/ handle/20.500. I 1822/7803/hydropolitical sp LA.pdf?sequence=5\&isAllowed =y

Roca, J. (2015). La china Huaneng completa la mayor central hidroeléctrica del Tíbet. El periódico de la energía (27.10.20I5). Recuperado de: https://elperiodicodelaenergia.com/la-china-huaneng-completa-la-mayor-central-hidroelectrica-del-tibet/

Rodríguez, M. (2018). El mayor trasvase de agua de la historia de China. Recuperado de: https://cincodias.elpais.com/ cincodias/20 I8/I2/I7/companias/I545063 I84_504455.html (I7.08.2020).

Rogers, S. y Crow Miller, B. (2017). The politics of water: a review of hydropolitical frameworks and their application in China. Wiley Interdisciplinary Reviews, 12 (39), I-I5, DOI: I0.1002/wat2. 1239

Schneiderman, S. (20/3). Himalayan border citizens: Sovereignty and mobility in the Nepal-Tibetan Autonomous Region (TAR) of China border zone. Political Geography, 35, 25-36.

Segrelles, J. (2007). Geopolítica del agua en América Latina. Dependencia, exclusión y privatización, Trabajo presentado en el XVI Simposio Polaco-Mexicano,Varsovia.

Selby, J. (2005).The geopolitics of water in the Middle East: fantasies and realities. ThirdWorld Quarterly, 26 (2), $329-349$.

Selby, J. y Hoffmann, C. (20I4). Beyond scarcity: rethinking water, climate change and conflict in the Sudans. Global 
Environmental Change, 29, 360-370.

South to North Diversion Project. Recuperado de:https://www.water-technology.net/projects/south_north/ (I6.08.2020).

Turton, A. y Henwood, R. (2002). Hydropolitics in the developing world: a Southern African perspective. Pretoria: University of Pretoria.

Urban, F., Siciliano, G., y Nordensvard, J. (2018). China's dam-builders: their role in transboundary river management in South-East Asia. International Journal of Water Resources Development, 34 (5), 747-770.

Velloso, M. (2018). La estrategia de China en la región del Himalaya. Consejo Argentino para las relaciones Internacionales. Recuperado de: http://www.cari.org.ar/temas/himalaya.html (23.05.2020).

Walcott, S. (2010). Bordering the Eastern Himalaya: Boundaries, Passes, Power Contestations. Geopolitics, I5, 62-8I, DOI: 10.1080/I 4650040903420396

Waterbury, J. ( 1 979). Hydropolitics of the Nile Valley. Nueva York: Syracuse University Press.

Wester, P., Mishra,A., Mukherji,A., y Shrestha,A. (2019). The Hindu Kush Himalaya Assessment Mountains, Climate Change, Sustainability and People. Kathmandu: Springer Open.

Yuan, C. (2018). China's Contingencies: Critical Geopolitics, Chinese Exceptionalism and the Uses of History. Geopolitics, 23 (I), 67-95. DOI: https://doi.org/10.1080/14650045.2017.1302429

Zeitoun, M. y Warner, J. (2006), Hydro-hegemony: a framework for analysis of trans-boundary water conflicts. Water Policy, 8, 435-460.

Zhang, H. (20I5). Sino-Indian water disputes: the coming water wars? Wiley Interdisciplinary Reviews: Water, 3 (2), I55-166. Recuperado de: https://doi.org/I0.1002/wat2.II 23

Zhang,H.y Li,M.(20 18).Hydropolitics and Conflict Management in Transboundary River Basins:China and its Neighbours. International Journal of Water Resources Development, 34 (5), 699-704. DOI: 10.1080/07900627.20 I8. I49920 I

Zhang, H. y Li, M. (20I8b). Editorial-Hydropolitics and Conflict Management in Transboundary River Basins: China and its Neighbours. International Journal of Water Resources Development, 34 (5), 699-704.

Zhang, H. y Li, M. (2018c). A process-based framework to examine China's approach to transboundary water management. International Journal of Water Resources Development, 34 (5), 705-73I. 


\section{RELACIONES INTERNACIONALES}

Revista académica cuatrimestral de publicación electrónica

Grupo de Estudios de Relaciones Internacionales (GERI)

Universidad Autónoma de Madrid, España

https://revistas.uam.es/relacionesinternacionales

ISSN 1699 - 3950

f facebook.com/RelacionesInternacionales

3. twitter.com/RRInternacional 